\title{
Inhaltsverzeichnis
}

vorbemerkung ..................... v

Einleitung ...................... 1

\section{Kapitel: Inkubation}

Einleitung. . . . . . . . . . . . . . . . 13

1. I. Kg. $35-15 \ldots \ldots \ldots$. . . . . . . . . . . 19

2. Gen. $2810-29,1 \ldots \ldots 27$

3. Gen. $4612-52 . \ldots \ldots . \ldots . \ldots 32$

4. Gen. 16. . . . . . . . . . . . . 35

5. 1. Sam. $3 \ldots \ldots$. . . . . . . . . . . . . . . 45

6. Inkubation in den Psalmen ............... 51

7. Jes. $654 \ldots \ldots \ldots 5$

Zusammenfassung ................ 55

Anhang: Inkubation in Assyrien und Babylonien ....... 56

Inkubation bei den Hethitern ............ 57

II. Kapitel: Die symbolischen Träume im A.T.

1a. Gen. $375-8 \ldots \ldots$. . . . . . . . . . . . . 58

b. Gen. $377_{\theta-10} \ldots \ldots \ldots 61$

2. Gen.40.................. 65

3. Gen, 41. . . . . . . . . . . . . . 74

4. Jud. $713-14 \ldots . . . . . . . . . . . . .885$

5. Dan. 2 . . . . . . . . . . . . . 90

6. Dan. 3 31-4, 34 . . . . . . . . . . . . . 113

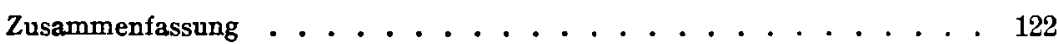

III. Kapitel: Befehle und Weisungen, die Gott durch den Traum übermittelt

1. Gen. 20................... 125

2. Gen. $3124 \ldots \ldots 131$

3. Gen. $3110-13$. . . . . . . . . . . . . . . 132

4. Vereinzelte Stellen. . . . . . . . . . . . . . 134

Zusammenfassung ................. 135 
IV. Kapitel: Der Traum als Offenbarungsmittel der Gottheit

1. Num. $126-8 \ldots \ldots 137$

2. 1. Sam. 28 6.15 . . . . . . . . . . . . . . . . . . . . . . . . 139

3. Joel 31 . . . . . . . . . . . . . . . . . . . . . . . 140

4. Hiob $412-16$. . . . . . . . . . . . . . . . . . . . . . . . . . 142

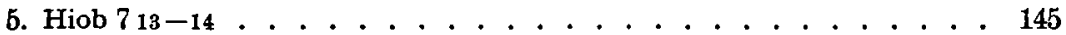

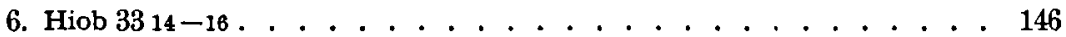

7. 2. Makk. $1511-16$. . . . . . . . . . . . . . . 148

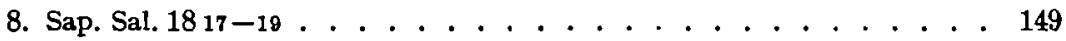

V. Kapitel: Der Traum im Vergleich

1. Jes. 297.8 . . . . . . . . . . . . . . . 151

2. Hiob 208 . . . . . . . . . . . . . . . . 153

3. Ps. 7320 . . . . . . . . . . . . . . . 153

4. Ps. $1261 \ldots \ldots 154$

VI. Kapitel: Die Ablehnung des Traumes als Offenbarungsmittel

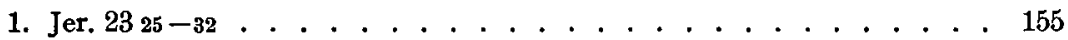

2. Jer. $270-10 \ldots \ldots$. . . . . . . . . . . . 158

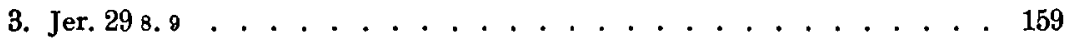

4. Dt. $132-6 \ldots \ldots \ldots 16 \ldots$

5. Sach.102. . . . . . . . . . . . . . . 162

6. Koh. $5(2) 6 \ldots \ldots$. . . . . . . . . . . . . . . . 164

7. Jes. Sir. $311-8 \ldots \ldots$. . . . . . . . . . . . . . . 164

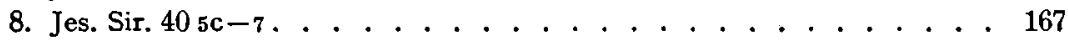

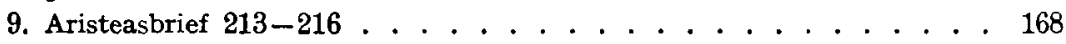

Zusammenfassung ...................... 169

Abkürzungsverzeichnis

I. Kommentarwerke . . . . . . . . . . . . . . . . 171

II. Zeitschriften und Sammelwerke . . . . . . . . . . . . 171

Verzeichnis der mehrmals zitierten Literatur . . . . . . . . . . . 173

Nachträge . . . . . . . . . . . . . . . . . . 178

Nachwort . . . . . . . . . . . . . . . . 179 